\title{
Attitudes of Chinese Immigrant Parents to the Heritage Language Maintenance Have Positively Affected Their Children's Chinese Learning in the United States
}

Wenting Zhou

University of Illinois at Chicago, Chicago 60607, USA

\begin{abstract}
This study explores the relationship between Chinese parents' language background and their children's performance of learning Chinese language in the United States. Since an increasing number of Chinese immigrant families brought their children to the Chinese language school, bilingual education in those kinds of families has raised specific notice recently. In this study, data collection included surveys, audio-taped interviews, observations, and students' Chinese language test scores. Those participants were divided into two groups, the students took the children's self-satisfaction questionnaire, and the parents took the demographic survey separately. Besides, the content of audio-taped interviews was transcribed as statistical variances to find and identify patterns of the results.
\end{abstract}

Those three research questions need to be answered in this study: 1. What are the attitudes and actions of those Chinese immigrant parents who do have regard to their Children's Chinese language and literacy learning? 2. Why do some parents feel challenged to maintain Chinese in the home and face the intense pressure of English usage outside society? 3. Is there any connection between Chinese heritage language proficiency and self-efficacy in learning? After the study, the results showed a positive relationship between Chinese heritage language proficiency and students' self-esteem. Parents who were most insistent on using Chinese in the home were most successful in maintaining their children's Chinese, and they also got a better score on the Chinese language tests.

Key words: Chinese immigrant families; Chinese language learning; Heritage language maintenance
Publication date: December, 2020

Publication online: 31 December, 2020

“Corresponding author: Wenting Zhou, 411087634@ qq.com

\section{Literature review}

The United States is a multilingual country, and especially nowadays, the global collaboration made companies recruit high-quality labors from overseas. As a result, the high volume of new immigrants lived in the United States and raised their children to become an essential part of the population. When they move to this new country, immigrants also brought their language and cultures with them. According to the data from Census Bureau, from April 1st, 2010 to July 1st, 2015, the Asian population was increased by $2,128,548$ for the "Net international migration" in the United States, which includes international migration of both native and foreign-born people. As the fastest growing group compared with other minorities in the U.S., 757,502 for Black/African -American, 27,515 for American Indian and Alaska Native, 31,518 for Native Hawaiian and Other Pacific Islander, 1,592,936 for Hispanic. (U.S. Census Bureau, 2016), educating those children of immigrants is a great challenge for regular classroom teachers if the immigrant family speaks a very different language than English at home, especially for Chinese immigrant families. Because unlike most languages, Chinese has a unique ideographic writing system that provides visual comprehensibility. The grammatical structure of Chinese is logical and pragmatic, which is related to the particular way of Chinese thinking. However, 
learning Chinese in the United States has a long history, which can be tracked back to when the first Chinese immigrant started to live in the U.S.

"As early as the nineteenth century, Cantonese class offered children of early immigrants residing in Chinatowns in a number of larger U.S. cities such as San Francisco and New York. Today, according to a 2005 Asian Social report, approximately 150,000 students are taking Chinese (primarily Mandarin) in community-based language school nationwide" (Agnes Weiyun He, Yun Xiao, Richard Schmidt, 2008). The Chinese language learning among those immigrant parents was very pervasive in the past time. However, when the second generation of those early immigrants grew up and became the new parents, it was more challenging to maintain Chinese in the home environment as they struggled with the intense pressure of English usage in the mainstream society.

\section{The identification of Chinese-American}

Yang, W. (2004) introduced that Chinese-Americans are a new immigration group, including both persons born in American and born in foreign countries, and they spend most of their lives in the United States. Most of them are maned "model monitory" today because they usually "demand and expect their children will do better in school" (Yang, W. 2004). As a result, parental influence and home environment are essential factors in those children's development, including language learning.

\section{The heritage of Chinese language in Chinese- American families}

Jiang, Y. (2009) found that the "parents from an academic background successfully reproduced and transferred a variety of cultural capital originating from their education and cultural resources in their home countries to support their children's first language (L1) and second language (L2) literacy learning in the host country" (Jiang, Y., 2009). From this finding, the social and cultural capital parents demonstrated in support of their children's Chinese learning are the center of research - the heritage language maintenance usually confused children who came from the new immigration families. Many of them had to lose their previous language like Chinese and shifted to English entirely. This finding explains some of the reasons why those students might have lower-efficacy in learning their heritage language. Because in the current educational environment, many of those are not encouraged to use their heritage language.

\section{Statement of purpose and research questions}

\subsection{Statement of purpose}

This study aims to find the relationship between Chinese immigrant parents' attitudes to heritage language maintenance and their children's Chinese learning. Besides, this study also determines how deeply the language background affects the performance of students learning Chinese.

According to my own teaching experience in the United States, I was a Chinese language teacher and helped students pass the AP test in an American private school for their senior year. I met some students who were growing in a multicultural family and always felt struggling and presented a dilemma in taking the language class. From my work, I gradually learned the differences between native Chinese speakers and children who are often referred to as "ABC" (American-born Chinese) by the first or second generation immigrant parents. As a result, it was a challenge to find suitable teaching methods for those particular students. During this study, I need to find out what is the internal and external reasons for my concern about why some students came from Chinese-speaking families tended to be insufficient in learning the Chinese language.

\subsection{Research questions}

(1) What are the attitudes and actions of Chinese immigrant parents who regard their Children's Chinese language and literacy learning?

(2) Why do some parents feel challenged to maintain Chinese in the home and face the intense pressure of English usage outside society?

(3) Is there any connection between Chinese heritage language proficiency and self-efficacy in learning?

\subsection{Null hypothesis}

There is no difference between the students who have heritage language maintenance in their Chinese immigrant family and the students who do not use heritage language at home to perform Chinese language and literature tests. 


\subsection{Alternative hypothesis}

Students who have heritage language maintenance in their Chinese immigrant family would score higher on Chinese language and literature tests than those who do not use heritage language at home.

\section{Method}

\subsection{Research approach and design}

This research includes data collection about the interviews, observations, and children's weekly test scores in Chinese class. I utilized the quasiexperimental design for analyzing the experimental group and the control group. I also applied the correlation and multiple regression to investigate the relationship between those various variables. The assumption would be that the parents who use Chinese as a heritage language at home could positively impact their children's Chinese language and literacy learning in school. Moreover, there is some connection between parents' maintaining heritage language at home and their children's selfesteem in learning Chinese.

Qualitative and quantitative designs and methodologies are applied to address the research questions. The parents' and children's surveys gather the quantitative data about the parents' general information and parental styles of their children's Chinese learning environment and language proficiency. Additionally, the survey collected the children's attitude to learning Chinese at language school. The qualitative study came from the Audiotaped interview and observations in parental perception.

\subsection{Research setting}

The research question setting is a survey with 10-15 questions about Chinese learning activities at home. For example, what kind of TV programs you and your parents watching most frequently at home? Do they use English or Chinese in those TV programs? And so on.

The research setting is a Chinese language school where have Chinese language and literacy classes on the weekend. As a Chinese teacher, I can access each level of Chinese courses and choose the students and parents I need for the research. I collected general information, such as the number of children, age, degree, salary, and language proficiency of children, for each family in school.

\subsection{Participants and sampling}

Most of the students who took Chinese language class are third and fourth grades in American public schools. As a result, they were already familiar with the teaching style of their teachers in public schools. Participants in audio-taped interviews included 25 pairs of parents randomly selected based on their children's grades in the language school. Most of them seldom speak Chinese at home, and their children learn Chinese only in the weekend Chinese language school.

\subsection{Instrumentation and measures}

Two surveys were conducted to collect data for quantitative analyses. To get full information about the parents and children, the Chinese language school held a meeting with all the participants and helped compile the questionnaires. If some participants cannot attend this meeting, a phone-survey with the same questions would be managed by the Chinese language school's directors.

All the answers to questions applies a 5-point response scale, and Yang, W. (2004) introduced the Parental Perception Survey (PPS), which is found in Appendix A. Besides, the measurement of each variable by coding them in different numbers or scores. For example, the variables that attend Chinese classes are 1 . The variables that don't participate in Chinese class are 0 , which used the dummy codes to analyze the dependent and independent variables' regression. The reliability depends on the answer from the interview with parents and children. The Chinese test scores are reliable and valid because we use a standardized test to get each sample's accurate score in the research.

\subsection{Limitations of design}

There are some limitations to this study.

First, data collecting, the sample is collected in a small language school in the Chicago area where the Chinese population is not very large. Moreover, Chinese-speaking immigrants is a small part of the community as other foreign language speaking immigrants in the United States. The study subjects came from students' parents, which means that it cannot generalize the results to the whole Chinese immigrant population.

Second, during the experimental process, since the 
observation in every family at home was challenging, it might happen that the research has inaccurate data collection about the parents' behaviors after school time. The language proficiency ratings depended on the score of Chinese language and literature tests in the language school. This data may not represent children's absolute ability in the questionnaire.

Third, because all the data are coming from selfreport, the results usually have some bias, and those parents' answers depend on their own experience, which makes the analyses less objective than the other data calculation.

\section{References}

[1] Agnes Weiyun He, Yun Xiao, Richard Schmidt, (2008). Chinese As A Heritage Language: Fostering Rooted World Citizenry. Honolulu, HI: University of Hawaii Press.

[2] Attaran, M., \& Yishuai, H. (2015). Teacher education curriculum for teaching Chinese as a foreign language. Malaysian Online Journal of Educational Sciences, 3(1), 3443.

[3] Jiang, Y. (2009). Social and cultural capital across contexts: Mandarin-speaking English language learning children's first and second language literacy learning at home, in the community, and multiple classrooms [D]. University of Illinois at Urbana-Champaign, 2009, URI: http://hdl.handle. net $/ 2142 / 80093$

[4] Jiening Ruan, Jie Zhang, Cynthia B. Leung, (2015). Chinese Language Education in the United States. Switzerland: Springer International Publishing.

[5] Kwoh, S. (2007) Mainstreaming and professionalizing Chinese-language education: A new mission for a new century. Chinese America: History and Perspectives, 261-264.

[6] Tam, F. W. (2009). Motivation in learning a second language: Exploring the contributions of family and classroom processes. Alberta Journal of Educational Research, 55(1), 73-91.

[7] Wang, J. (2013). Factors influencing Chinese immigrant children's heritage language maintenance: An application of social network analysis and multilevel modeling [D]. Michigan State University, 2012, https://doi.org/doi:10.25335/M5SH8D

[8] Yang, S. (2008). Narrative of a cross-cultural language teaching experience: Conflicts between theory and practice. Teaching and Teacher Education, 24(6), 1564-1572. doi: 10.1016/j.tate.2007.12.003

[9] Yang, W. (2004). Perceptions of high socio-economic ChineseAmerican parents about their children's academic achievement, home environment, and Chinese language proficiency [D]. University of Connecticut, 2004, https://opencommons.uconn. edu/dissertations/AAI3156430

[10] Zhao, A., Dynia, J., \& Guo, Y. (2013). Foreign language reading anxiety: Chinese as a foreign language in the United States. Modern Language Journal, 97(3), 764-778. doi: 10.1111/j.1540-4781.2013.12032.x 